\title{
Control of DFIG on Variable Wind Speed
}

\author{
N. Khan ${ }^{\mathrm{a}}$, N. $\operatorname{Abas}^{\mathrm{a}, \mathrm{b},{ }^{*}, \text { T. Bukhari }}{ }^{\mathrm{a}}$ \\ ${ }^{a}$ Department of Electrical Engineering, COMSATS Institute of Information Technology, Islamabad, Pakistan \\ ${ }^{b}$ Department of Electrical Engineering, University of Gujrat, Hafiz Hayat Campus, Gujrat, Pakistan
}

\begin{abstract}
Doubly Fed Induction Generator (DFIG) is one of the most reliable wind generator. Major problem in wind power generation is to generate constant frequency output on variable speed. This paper summarizes \& reviews major techniques used in DFIG, and investigate various technologies developed by and solution proposed by different researchers to maintain constant frequency. In addition authors proposed method on these issues is discussed and experimental results are also included. DFIG experiment is demonstrated by driving it with a motor instead of real wind turbine. A variable frequency drive will be used to cause drive motor speed variations. Control circuit is attached with rotor windings, which will try to maintain the rotor excitation constant during speed variations. Proposed DFIG model controls the rotating magnetic field of the rotor in such a way that stator frequency becomes independent of RPM. Experiment is successfully performed on $+/-12 \%$ speed variations.
\end{abstract}

Keywords: DFIG; VFD, constant frequency, wind power generation, pitch control.

\section{Introduction}

Energy crises, supply uncertainties and environmental concerns are driving the effort to rethink the global energy portfolio. For example, European wind energy association has set target to supply $23 \%$ of their total demand through wind by the end of 2030 [1]. Power extraction from the wind is not a new concept, it's being used from thousands of years like moving of ships in sea, wind mills etc. Electricity production from wind turbines has been the focus of considerable attention since long, as everybody knows that fossil fuels become depleted by the end of this century. Out of all the renewable sources, wind power is the most exploitable form of energy. As there are many areas where winds blow 24 hours a day, like coastal regions. Wind never blows with constant velocity. It changes its speed, density and temperature several times a day. In this scenario, it becomes really difficult for generator to maintain constant output (voltage and frequency) which is necessary for grid synchronization [2]. Modern advancement in power electronics has made this possible.

${ }^{*}$ Corresponding author. Tel.: +923005879115

Fax: +92 (53) 3642167; E-mail: naeemk56@yahoo.com;

(C) 2015 International Association for Sharing Knowledge and Sustainability

DOI: $10.5383 /$ ijtee. 10.02 .008
To harness the wind power the most reliable method is grid connected Doubly Fed Induction Generator (DFIG). The following lab equipments were used to build DFIG laboratory model and to simulate actual wind situations: Siemens $4.7 \mathrm{KW}$ slip ring induction generator, $3 \mathrm{HP}$ induction motor as prime mover, Invent variable frequency drive, capacitors, bulbs as load, oscilloscope, and control circuit including resistors, capacitors \& BJTs. Ratings of these equipments can be found in detail circuit diagram. There are two types of induction machine, squirrel cage induction machine and wound rotor induction machine. Rotor of squirrel cage induction machine contains aluminum bars and is short circuited. Rotor of wound rotor induction machine has same winding as that of the stator. Leads from them are brought out and are attached to slip rings which are mounted on the armature [3]. This paper will concentrate on study of wound rotor induction machines.

Assuming a three phase system, when supply is given to stator of induction machine, current flows through its coils and magnetic field is developed. This magnetic field is rotating and called rotating magnetic field (RMF) as shown below. 
The speed of RMF at stator is given by

$$
n_{\text {sync }}=\frac{120 f}{P}
$$

Where $\mathrm{f}$ is the frequency and $\mathrm{P}$ is the number of poles. If the stator supply frequency is increased or decreased, the RMF will also increase or decreases. When this magnetic flux interacts with rotor windings it induces current in it. Whenever current carrying conductor is placed in rotating magnetic field it experience a force in RMF direction called Lorenz force [4], given by

$$
F=l I \times B
$$

This force is responsible for induction machine working as a motor. If rotor reaches the synchronous speed, the induced current becomes zero and motor stops. That's why rotor always lags the synchronous speed by factor called slip [4], given by

$$
\text { Slip }=\frac{\boldsymbol{n}_{\text {sync }}-\boldsymbol{n}_{m}}{\boldsymbol{n}_{\text {sync }}}
$$

Where $n_{m}$ is the rotational speed of rotor. Slip is generally a small quantity usually $3 \%$ to $4 \%$.

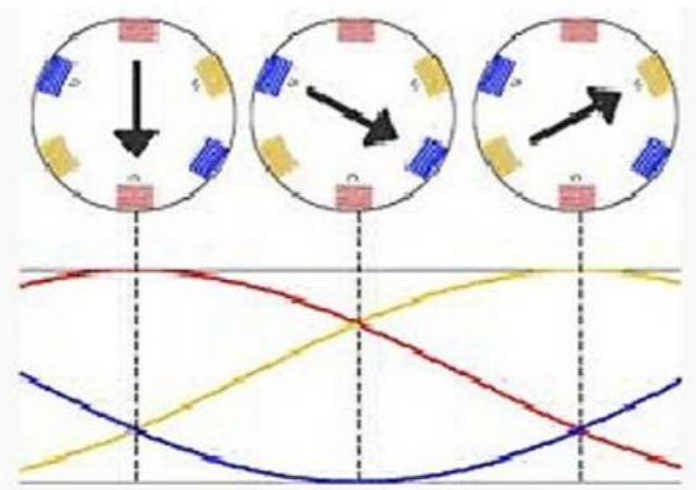

Figure 1. Rotating Magnetic Field.

If the slip is in between 0 and 1 the machine will act as motor and if slips becomes negative it will behave as generator, can be described by figure below.

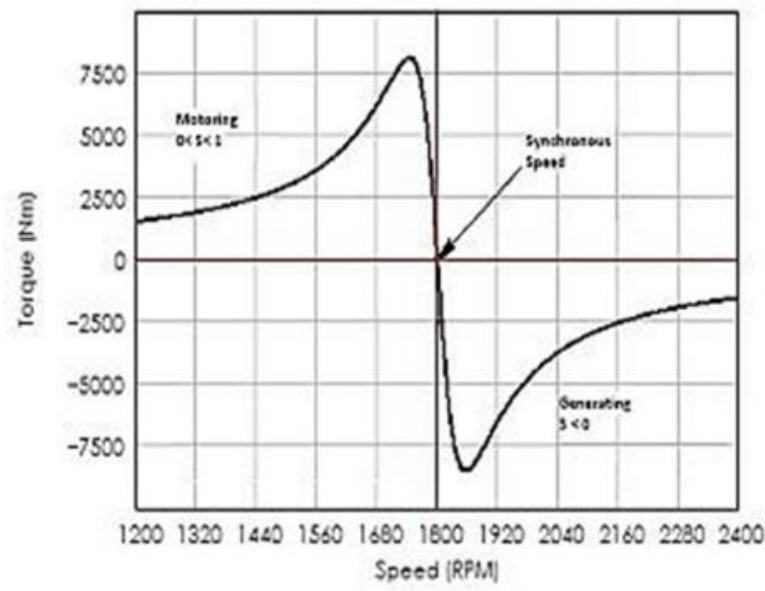

Figure 2. Torque- slip characteristics of Induction Machine [3]

\section{Doubly Fed Induction Machines}

DFIG is one the most widely used wind generator. DFIG has two modes of operation i.e. sub-synchronous mode and supersynchronous mode. At synchronous speed DFIG acts like a synchronous generator, in sub synchronous speed slip power is supplied to the rotor to maintain its excitation through AC-DCAC link. In super synchronous speed, extra slip power is taken out of rotor through the AC-DC-AC link and feed in to the grid. By doing this, excitation at rotor remains constant and output at stator is always up to grid standards. Stator is directly connected to grid, and rotor is connected through AC-DC-AC link. This link gives slip power to rotor is sub synchronous mode and takes slip power from the rotor in super synchronous mode. DFIG is only generator which gives access to its rotor windings. Excitation of rotor is maintained by accessing the rotor windings externally. AC-DC-AC link is used for this purpose. There are many techniques developed by different researchers to control the rotor excitation and frequency [5]. DFIG detail diagram is shown in figure 3.

The AC-DC-AC link is controlled using a control circuit; inverter and converter both use the PWM technique to operate. There are many PWM techniques like sinusoidal PWM technique, space vector PWM technique.

Vector control algorithms are most widely used in DFIG control, in which flux linkages between rotor and stator is examined [6]. Many other control schemes like fuzzy logic [7], matrix control have been developed by different researchers to improve DFIG performance [8].

As this paper mainly deals about the frequency control strategies of DFIG, so control circuit will be analyzed with respect to frequency controlling.

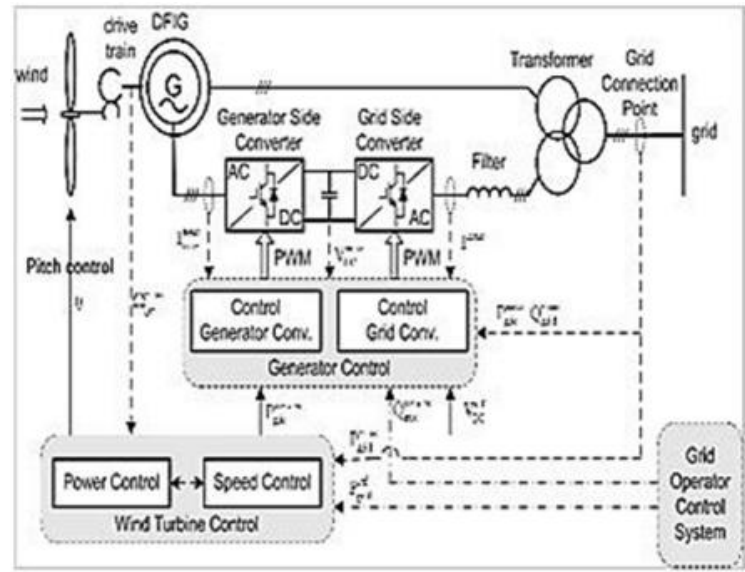

Figure 3. DFIG modern day model [3]

\subsection{Frequency Control of DFIG}

There are many techniques to control the DFIG rotational speed; some of them are as under.

\subsubsection{Pitch Control}

For successful operation of DFIG on $+/-30 \%$ speed variations, pitch control is necessary. Pitch control has really helped modern wind power plants to increases there ranges of stable operation and efficiency [9].

Pitch control reduces the angle of attack of air on the blades of the turbine. It means blades of turbine are moveable and can adjust themselves with wind speeds to face as much air as required. During high wind strokes pitch control makes the 
blades to be in line with wind and very little part of blade faces the wind. This is the most widely used way of maintaining the rotor speed near to synchronous. Control circuit senses any change in rotor speed and generates signal to pitch angle controlled to change its position. As, pitch control involves the mechanical movement, so it takes some time. During this time period, control circuit uses its AC-DC-AC link to maintain the rotor excitation either by giving or by extracting slip power from the rotor. If the wind speed increases the pitch control range then wind turbine is cutoff and brought offline.

Pitch control has becomes the necessary part of wind turbines now a days. If wind power plant uses any other way to reduce the shaft speed, it will use pitch control as well.

\subsubsection{Changing Gear-Box Assembly}

The classic way of controlling the mechanical torque is by using gear box assembly. In modern wind power plants normally three stage gear box are used. This gear box is placed between the wind turbine and the generator. Gear box prime objective is to match the wind turbine rotational speed with the synchronous speed of generator. Control circuit is the driving body which generates signal for the gear box to increase or decrease it stages. Gear box always maintains a constant and increasing speed ratio [10].

\subsubsection{Inverter attached with Stator}

DFIG is surely better than all other wind generators but still it's a limited speed wind generator. To increase its performance if a frequency inverter is attached with stator it can with stand on even more then $+/-30 \%$ speed variations. Extra slip power generated during high wind speeds can be extracted out from rotor. Using this concept along with pitch control is widely used now days. Power coming out from stator is converted to grid friendly parameters using frequency inverter and then connected to grid [11].

\subsection{Proposed Concept of Controlling DFIG Frequency}

To achieve constant frequency on variable speeds rotor excitation is controlled in such a way that frequency becomes independent of rpm. Frequency only depends on rpm and poles, that's why all present DFIG models using different methods described above to maintain rotor speed near to synchronous. In order to describe the proposed method control strategy, understanding of frequency generation in necessary.

The rotor of synchronous generator is also wounded but feed with DC supply. It means north and south poles becomes fixed and there is no rotating magnetic field. When rotor rotates it cuts the poles of stator and induces voltage in it. It means by moving the rotor, rotating magnetic field is intentionally created. If generator is of 6 poles, rpm required to produced 50 $\mathrm{Hz}$ frequency is given by

$$
f=\frac{P N}{120}
$$

It means that if the magnetic field on the rotor cuts each pole of stator 1000 time in a minute, $50 \mathrm{~Hz}$ frequency is generated. Now, instead of rotating rotor on $1000 \mathrm{rpm}$ if the rotor magnetic field is rotated on $1000 \mathrm{rpm}$ the same frequency can be generated. In case of synchronous generator this is not possible as rotor is given DC supply but in case of DFIG this is possible as rotor is given AC supply which has varying magnetic field.

The above concept is used in this proposal to control the frequency. When rpm decrease from synchronous speed, frequency on the rotor is increased; so that it cuts the stator poles same number of times as rotor on synchronous speed would have. Similarly, as rpm increases from synchronous speed, the rotor frequency is decreased. By adopting this strategy frequency is maintained constant on +/- $12 \%$ variations with respect to synchronous speed. In case of induction motor when 3 phase supply is given on the stator RMF was established, this RMF depends on the supply frequency and poles. Poles are constant, so if supply frequency is changed RMF speed can be increased or decreased. In case of DFIG, 3 phase supply is given on the rotor. So RMF will be developed there, this RMF will start cutting the stator poles and induces voltage in it on the frequency depends on its speed. In this method RMF speed is controlled so that it cut the stator poles same number of times as much required for $50 \mathrm{~Hz}$ frequency irrespective of the rotor speed. Below figure shows clearly, that 3 phase supply is given to the rotor. RMF is developed, which start cutting the stator poles. In this experiment the RMF speed is controlled to obtain the desired frequency.

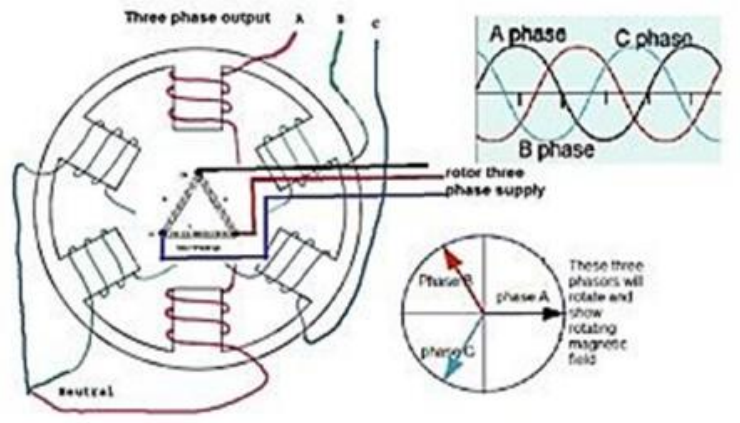

Figure 4. Proposed concept

\section{Experimental set up.}

This paper describes another way to manage frequency without using any pitch control or any other conventional method. If this technique is implemented with pitch control then DFIG efficiency can be increased and it can withstand on more than $+/-30 \%$ variations. In this paper in order to improve DFIG and operate it with a simple scheme, improved DFIG model proposed is shown below.

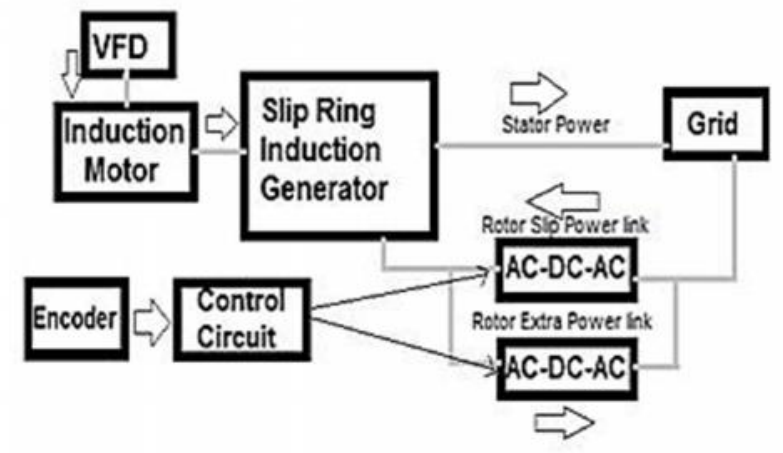

Figure 5. Proposed DFIG model

Grid connections are not being established. Separate load on stator and rotor are attached. Slip-ring induction generator is mechanically attached with induction motor. Induction motor is driven by VFD. VFD is used to simulate exact wind situations; prime mover is moved on variable speeds through VFD and experiments are performed. AC-DC-AC links are controlled by control circuit. The rotor of induction generator is always 
connected with the grid to maintain its excitation. 220 volt $\mathrm{AC}$ input is stepped down to 24 volt using transformer, this 24 volt $\mathrm{AC}$ is converted to $\mathrm{DC}$ and then again converted to $\mathrm{AC}$ using control circuit. This desired AC supply is connected with rotor of DFIG. Separate AC-DC-AC link is made to extract extra slip power of rotor. The lab setup is as under.

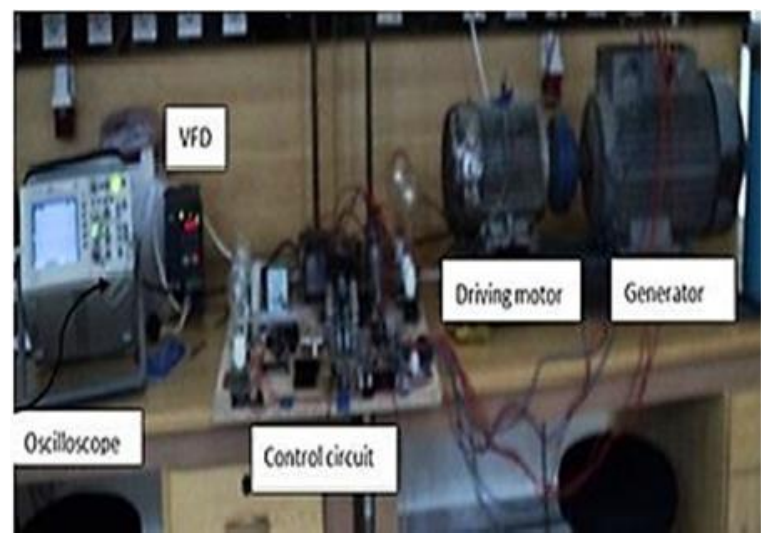

Figure 6. Laboratory Setup

\subsection{Control Circuit}

Control circuit basic purpose is to operate the inverter and to produce as much frequency as required. For this purpose BJTs D1047 are used in Darlington pair configuration. And they are driven by PWM IC SG3525. DFIG experiment control circuit is shown below.

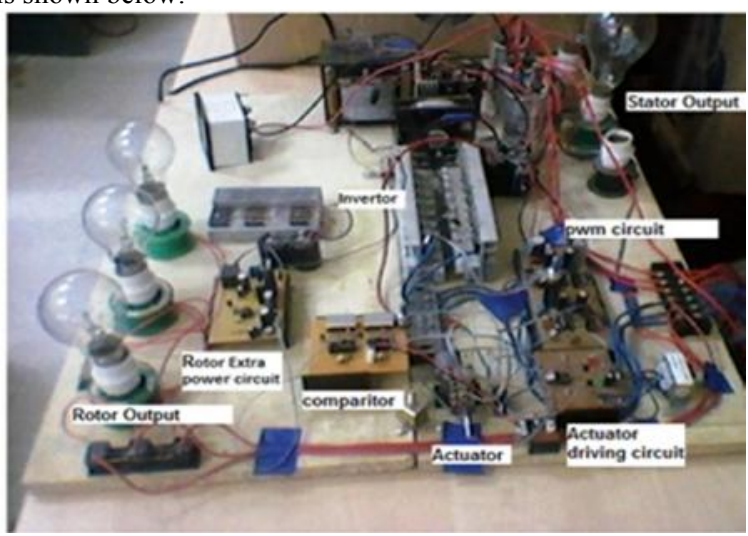

Figure 7. Control Circuit

\subsection{Design of Inverter}

Rotor of generator used has delta winding on it [12]. Inverter used for the experiment is similar to modern day UPS. DC +24 volt is given to one end of rotor winding; other two ends are given -24 volts. Square wave is generated at its output. It is really easy to achieve high frequencies using this type of inverter. It is shown below.

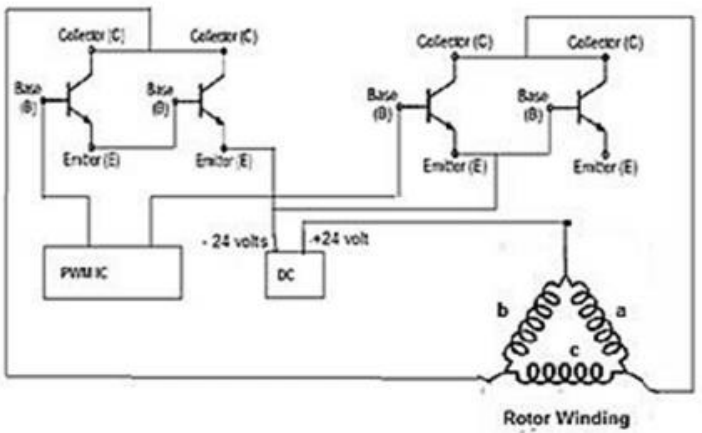

Figure 8. Inverter circuit

Output waveforms are taken using oscilloscope. The wave forms at synchronous speed are given below.

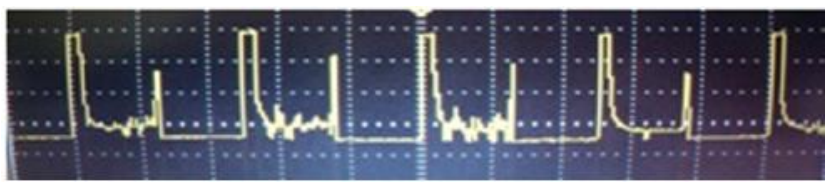

(a)

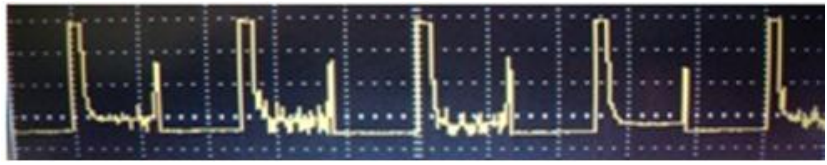

(b)

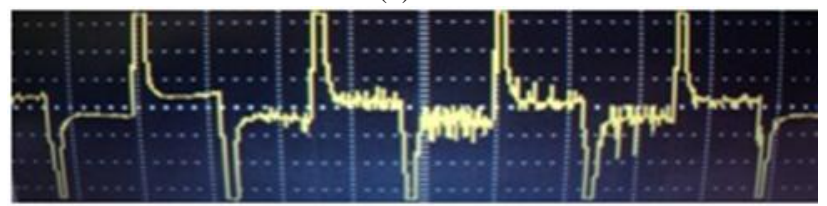

(c)

Figure 9. Inverter AC waveforms. (a) Wave form at point a. (b) Wave form at point $\mathrm{b}$. (c) wave form at point $\mathrm{c}$.

\subsection{PWM Circuit}

BJTs are operated using PWM technique. To generate PWM an IC SG3525 is used, it has a built in oscillator and uses sinusoidal PWM technique to generate its PWM [13]. Circuit used with IC is shown in figure 10 .

There is a PWM adjustment point between pin 5 and 16 . When voltage between these pins are increased the PWM decreased and when voltage is increased the PWM decreases. A potentiometer is used for this purpose from which the PWM was controlled during the experiment. Firstly, the frequency was measured at synchronous point. During, sub-synchronous speeds the potentiometer was manually operated and frequency at the rotor is increased until stator frequency reaches $50 \mathrm{~Hz}$. Similarly on super- synchronous speeds, frequency is decreased at rotor by adjusting potentiometer, and frequency is decreased unless stator frequency reaches $50 \mathrm{~Hz}$. 


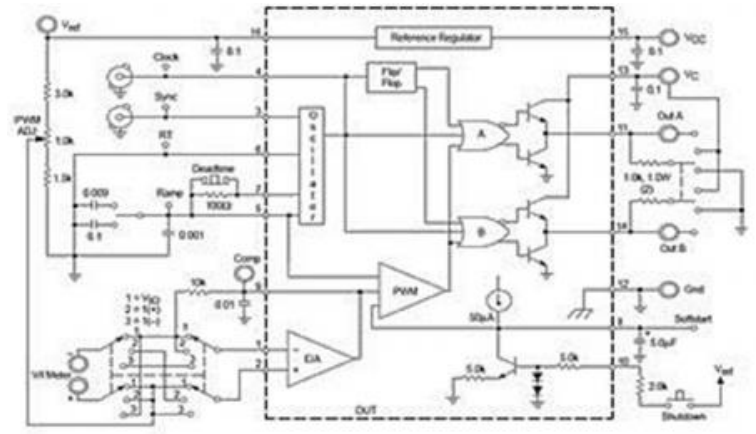

Figure 10. PWM generation circuit using IC SG3525

\subsection{Encoder}

It is attached just above the rotor shaft; some marks are place on the rotor shaft as well. When these marks cut the permanent magnet of the encoder pulses are generated. Theses pulses are converted in to DC using rectifier. DC voltage will increase as rpm increases and decreases as rpm decreases. The output of encoder is given to the comparator circuit.

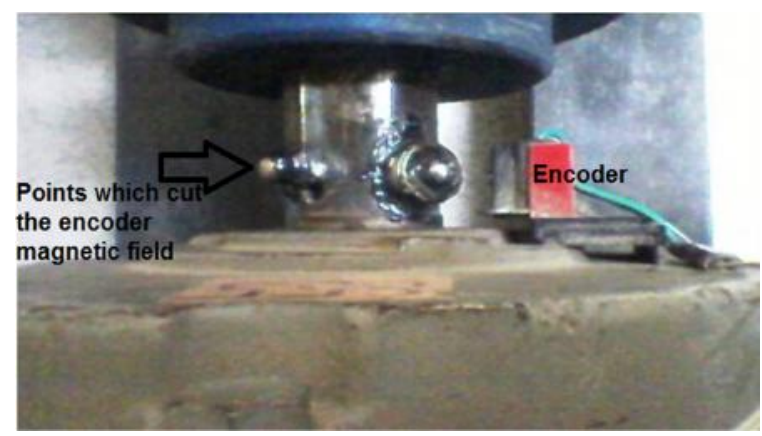

Figure 11. Encoder

\subsection{Comparator Circuit}

This circuit takes input from encoder and decides when to take extra slip power from the rotor to ensure its safe operation.

For this purpose, IC LM 3914 is used [14]. This IC has 10 output pins and unique ability to activate output pins one by one as its input voltage increases. LED bar display is also attached to each output pin. LED glows as pin got activated. During the experiment IC setting was made such that at synchronous speed 5th LED got ON. Any rpm below synchronous are shown by LED 1 to 4 and rpm above synchronous are shown by LED 6 to 10. As, extra slip power has to be brought out in super synchronous mode, so a transistor is attached between pin 6 to 10 . When transistor got triggered it will activate the circuit attached to it. By using this strategy following circuit was designed.

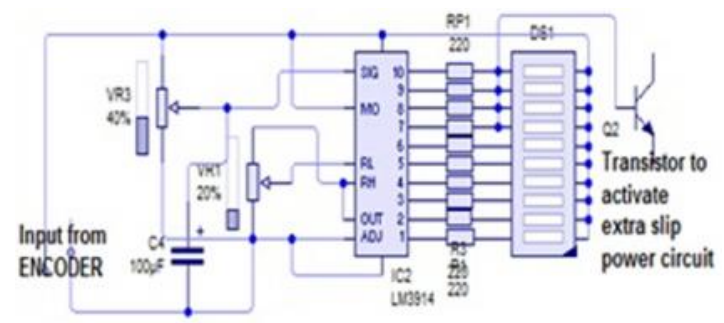

Figure 12. Comparator Circuit

\subsection{Rotor Extra Power Circuit}

When the transistor got triggered it means it's the time to activate the rotor extra power circuit. As generator is in super synchronous mode and extra power induced at rotor can make the generator to burn. Three 100 watt bulbs are attached with rotor leads as load, 5 pin relays are used and IC UA-741 is used to activate the relays. UA-741 is a simple operational amplifier, which got triggered as input increases a certain level and passes Vec attached to it. Its circuit diagram is shown below.

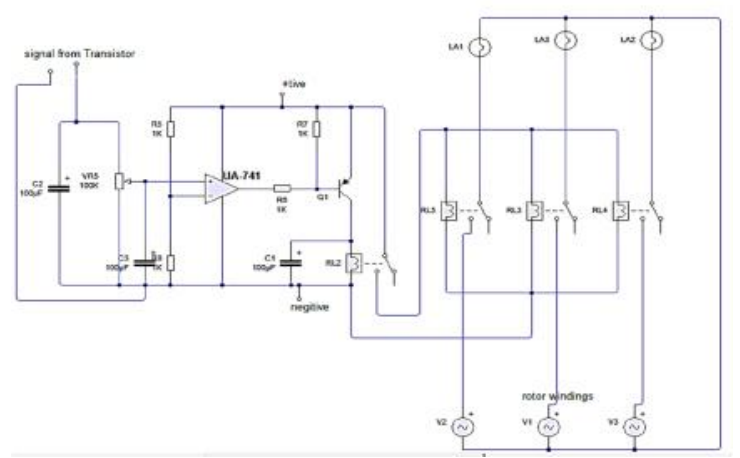

Figure. 13. Rotor Extra Power circuit

When the transistor got OFF, all the relays also got off and stops extracting power from the rotor.

\section{Results}

Induction generator used is a 6 pole machine. After dozens of experiments performed in laboratory it was founded that new synchronous point is $950 \mathrm{rpm}$. Reading measured using oscilloscope at this point are shown below.

TABLE 1. Initial Readings

\begin{tabular}{|l|l|l|l|l|l|l|}
\hline RPM & \multicolumn{2}{|l|}{$\begin{array}{l}\text { Rotor Voltage } \\
\text { (v) }\end{array}$} & $\begin{array}{l}\text { Rotor } \\
\text { Frequen } \\
\text { cy(Hz) }\end{array}$ & $\begin{array}{l}\text { Stator } \\
\text { Voltage } \\
(\text { V) }\end{array}$ & $\begin{array}{l}\text { Stator } \\
\text { Frequen } \\
\text { cy (Hz) }\end{array}$ \\
\hline 950 & 2 & 23 & $\begin{array}{l}3 \\
6\end{array}$ & 450 & 126 & 50 \\
\hline $850-950$ & 3 & 28 & $\begin{array}{l}4 \\
0\end{array}$ & $450-700$ & $\begin{array}{l}100- \\
120\end{array}$ & $49-51$ \\
\hline $\begin{array}{l}950- \\
1050\end{array}$ & 2 & 22 & 3 & $450-30$ & $\begin{array}{l}140- \\
190\end{array}$ & $49-51$ \\
\hline
\end{tabular}

As seen from above results the frequency at output remains constant, waveforms are same on all the three phases, figured as under.

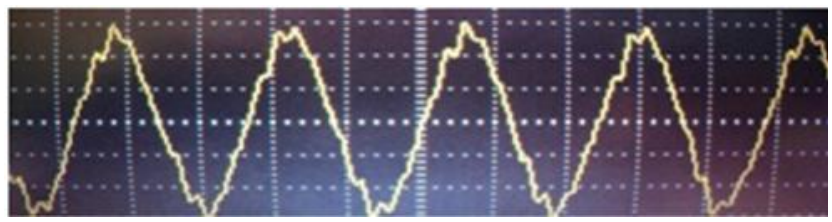

Figure 14. Stator output waveform

During rpm above the synchronous, frequency at the rotor is decreased along with it extra slip must have to be taken out, because extra power can burn the rotor windings. The output taken from the rotor terminals are shown below. 


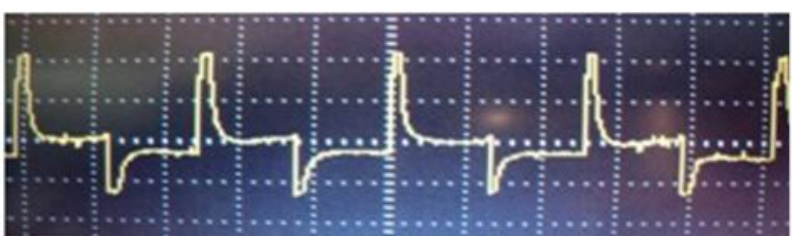

Figure 15. Rotor Extra Slip power Output Waveform

RPM against frequency graph is shown below.

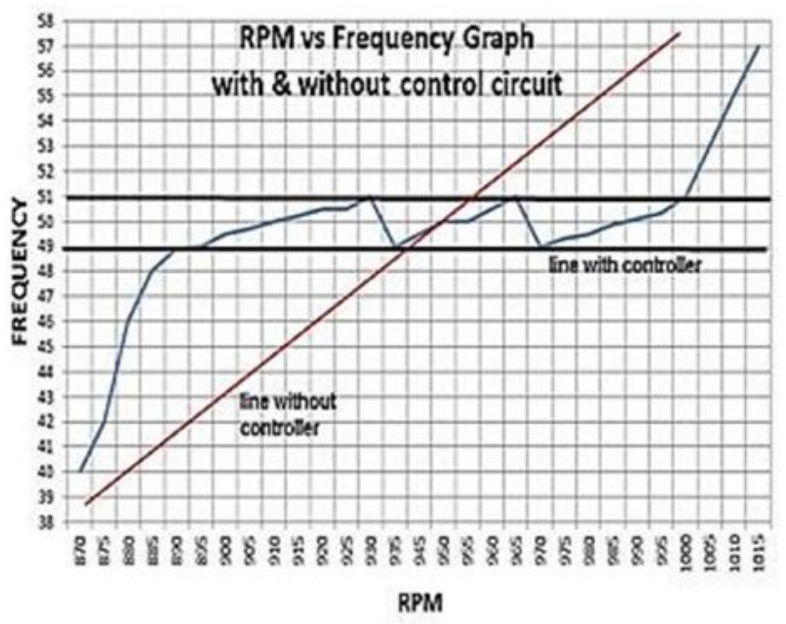

Figure 16. RPM vs Frequency graph

\section{Conclusion}

In this experiment a new method to control DFIG output frequency is proposed. DFIG was successfully tested on +/- 12 $\%$ speed variations. This work can enhance the present day DFIG knowledge. If proposed method is implemented using FPGA controller and pitch control then its performance \& efficiency can be increased and it can with stand on even $+/-40$ $\%$ variations. In future I will be looking forward to implement DFIG using vector control algorithms and implement it in real wind conditions.

\section{References}

[1] U.S. Department of Energy, 20\% Wind Energy by 2030: Increasing Wind Energy's Contribution to U.S. Electricity supply. Washington D.C.: U.S. Department of Energy, July 2008, p. 1,6.

[2] Wei Qiao and Ronald G. Harley, "Grid Connection Requirements and Solutions for DFIG Wind Turbines", IEEE Energy 2030 Conference, 2008.ENERGY 2008.
[3] Joshua Earnest, Tore Wizelius, "Wind power plants and project development", PHI, 2011.

[4] Ben Ranayhossaini, Chris Rekiel, Joseph E. Warner," Laboratory Experiments on a Doubly Fed Induction Generator (DFIG) for Wind Turbine Application", ASEE North Central Sectional Conference, March 26 $-27,2010$.

[5] Marco Liserre, Senior Member, IEEE, Roberto Cárdenas, Senior Member, IEEE,MartaMolinas, Member, IEEE, and José Rodríguez, Fellow, IEEE, "Overview of Multi-MW Wind Turbines and Wind Parks", IEEE TRANSACTIONS ON INDUSTRIAL ECTRONICS, VOL. 58, NO. 4, APRIL 2011.

[6] Arantxa Tapia, Gerardo Tapia, J. XabierOstolaza, and José Ramón Sáenz," Modeling and Control of a Wind Turbine Driven Doubly Fed Induction Generator", IEEE TRANSACTIONS ON ENERGY CONVERSION, VOL. 18, NO. 2, JUNE 2003.

[7] H. Karimi-Davijani, A. Sheikholeslami, H. Livani ,' Fuzzy Logic Control of Doubly Fed Induction Generator Wind Turbine", World Applied Sciences Journal 6 (4): 499-508, 2009.

[8] L. Zhang, C. Watthansarn and W. Shehered," A matrix converter excited doubly-fed induction machine as a wind power generator,'IEEE IECON Conf. Proc., vol. 2, pp. 906 - 911, Nov. 2004.

[9] S.Li, T.A. Haskew, "Analysis of Decoupled d-q Vector control in DFIG back-to-back PWM convertor', IEEE PES, JUN 2007.

[10] HenrikStiesdal, "The Wind Turbine, Components and Operation." Wind Mission , Autumn 1999, p. 13 [Online].

Available:http://www.windmission.dk/workshop/Bon usTurbine.pdf, [Accessed: December 2009],.

[11] Fleming Buss Bendixen, Gert Karmisholt Andersen, "Variable Speed Wind Turbine With Doubly Fed IndcutionGnerator Compensated for Varying Rotor Speed", United states Patents, sep 21, 2010.

[12] Wikipedia, "Inverter", URL: http://en.wikipedia.org /wiki/Inverter _(electrical) [Date Retrieved: Dec 2011].

[13] Motorola,"sg-3525 Data sheet', URL:www.designnet.com[Date Retrieved: Dec 2011]

[14] National-semiconductor," LM3914”, URL: www.national.com[Date Retrieved: Dec 2011]

[15] ST," UA-741 Data Sheet", URL:www.st.com, [Date Retrieved: Dec 2011.

[16] Wikipedia,“DFIG”,URL:http://en.wikipedia.org/ wiki/ Doubly_fed_electric_machine [Date Retrieved: Dec 2011]. 